\title{
POSSIBILIDADES DE UTILIZAÇÃO DO CINEMA NO PROCESSO DE ENSINO-APRENDIZAGEM DE HISTÓRIA: UM ESTUDO DE CASO EM ESCOLA DE CAMPO BOM-RS
}

\author{
POSSIBILITIES OF USING THE CINEMA IN THE HISTORY TEACHING-LEARNING \\ PROCESS: A CASE STUDY OF THE CAMPO BOM- RS SCHOOLS
}

\author{
Vitória Duarte Wingert ${ }^{1}$ \\ Márcia Blanco Cardoso ${ }^{2}$
}

\begin{abstract}
RESUMO: A presente pesquisa propõe-se a discutir o uso do cinema em sala de aula pelos professores de História, e como se dá essa formação e planejamento por parte dos docentes. A partir disso foi realizado um estudo com os professores de História da rede municipal de ensino de Campo Bom/RS, reconhecida por espaços de formação continuada e estrutura adequada para utilização de tecnologias em sala de aula. A metodologia utilizada foi a pesquisa bibliográfica, além de pesquisa qualitativa a partir de entrevistas estruturadas. Verificou-se que os professores utilizam esse recurso de variadas e criativas formas, como possibilidades de reflexão e análise de conceitos, épocas e alguns, inclusive, realizando produção fílmica.
\end{abstract}

Palavras-chave: Ensino de história. Cinema. Cinema em sala de aula. Campo Bom - rs.

\begin{abstract}
The present research proposes to discuss the use of cinema in the classroom by History teachers, and how this graduation and planning by teachers is given. Based on this, a study was carried out with History teachers of Campo Bom/RS municipal school system, recognized for continuing education spaces and adequate structure for use of technologies in the classroom. The methodology used was the bibliographic research, besides qualitative research based on structured interviews. It was verified that the teachers use this resource of varied and creative forms, as possibilities of reflection and analysis of concepts, times and also producing films.
\end{abstract}

Keywords: History teaching. Cinema in the classroom. Campo Bom - rs.

1 Doutoranda em Diversidade Cultural e Inclusão Social- Universidade Feevale. Mestra em Processos e Manifestações Culturais pela Universidade Feevale. Professora concursada na Rede Municipal de Campo Bom. Email: vitoriawingert@hotmail.com

2 Mestrado em Estudos Históricos Latino-americanos pela Universidade do Vale do Rio dos Sinos Unisinos. Professora adjunta da Universidade Feevale. 


\section{Introdução}

O presente trabalho versa sobre alguns dos resultados obtidos na pesquisa final do Trabalho de Conclusão de Curso (TCC) em História - Licenciatura pela Universidade Feevale, que teve como objetivo "refletir sobre a importância do cinema como recurso didático nas aulas de História e as possibilidades de utilização desse recurso".

Optamos então, por realizar uma pesquisa com enfoque local na Rede de

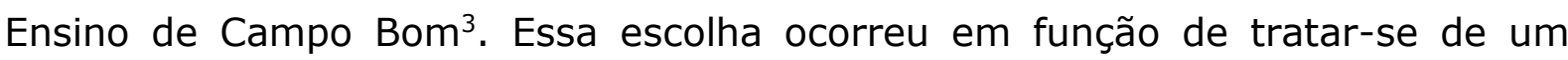
município que, desde o ano de 2009, vem investindo diversos recursos financeiros na área de Tecnologias aplicadas à Educação. Atualmente todas as salas de $1^{0}$ a 90 ano contam com lousas interativas, notebooks e projetores, desta forma os professores que desejam utilizar filmes ou documentários em suas aulas não encontram empecilhos (como a falta de equipamentos), diferente da realidade encontrada em outras redes municipais, com menos recursos, por exemplo.

Através dessa pesquisa com os professores de História de Campo Bom, buscamos refletir como o cinema vem sendo utilizado pelos professores em suas aulas, e se as metodologias aplicadas alçam os objetivos esperados por eles, tendo como foco o processo de aprendizagem. Uma vez que o cinema pode enriquecer uma aula, desde que utilizado com métodos que estimulem a reflexão e curiosidade dos educandos, orientando-os a interpretar e dialogar com o filme, levando em consideração a fonte histórica que o mesmo representa.

Inicialmente, será desenvolvida uma reflexão sobre o ensino de História, abordando possibilidades de utilização do cinema em sala de aula, visando uma aprendizagem significativa. Posteriormente apresentaremos alguns relatos de como os professores da Rede de Ensino pesquisada utilizam os filmes em sala de aula, uma vez que o uso do cinema como recurso didático nas aulas de História não é algo novo, já que o vemos sendo usado em diversas escolas, principalmente pelos professores de História. Esses professores, na busca por aproximar os alunos do conteúdo a ser estudado, muitas vezes utilizam os

3 Município situado na região metropolitana do Estado do Rio Grande do Sul. 
filmes, como um retrato de época ou até mesmo como uma verdade histórica. (NAPOLITANO, 2011)

Além disto, buscamos compreender como os saberes docentes constroem o perfil do professor e interferem diretamente em sua prática pedagógica e na escolha dos recursos que este utiliza em suas aulas.

\section{O cinema em sala de aula}

O cinema é utilizado em sala de aula, há muito tempo, isto não é nenhuma novidade. Segundo Bittencourt (2011), desde 1912 o professor do Colégio Pedro II e escritor de livros didáticos, Jonathas Serrano, incentivava o uso de obras cinematográficas ficcionais ou documentais em sala de aula, pois considerava este recurso mais efetivo que a memorização de datas históricas e grandes eventos, considerando os filmes uma "ressurreição histórica".

Mocellin (2009) destaca também no âmbito brasileiro os intelectuais ligados a Escola Nova, ou História Progressiva, estes buscavam a ruptura com o modo tradicional de ensino centrado no professor como único detentor de conhecimento, encontraram no cinema e nos meios de comunicação ferramentas para aproximar o conteúdo de sala de aula com a sociedade em que o aluno está inserido, porém estas medidas nunca foram implantadas na escola regular.

Para Bittencourt (2011, p. 372), "Apenas recentemente a escola tem iniciado uma aproximação mais realistas com estes meios de comunicação". Para esta autora também é recente a preocupação com os métodos didáticos da utilização dos filmes em sala de aula,

cabe indagar que trabalhos os professores têm efetivamente realizado com a linguagem cinematográfica: usam-na como ilustração de um tema de aula? Trabalham como se fossem ressurreições históricas? São analisados como veículos da ideologia dominante? (BITTENCOURT, 2011, p.372).

Uma vez que:

Cineastas e historiadores acadêmicos, de qualquer forma, influenciam como a sociedade olha para o passado. Porém não se pode afirmar que as versões do passado que eles apresentam 
sejam de uma forma absoluta, verdadeiras. Tanto historiadores quanto cineastas enfrentam alguns problemas metodológicos que se assemelham (BALDISSERA; RUINELLI, 2014, p. 24-25).

Também devemos levar em consideração o que querem a escola e os professores de história, trabalhem ou não, com cinema em sala de aula. Os filmes fazem parte do cotidiano tanto dos alunos quanto dos professores, o acesso às obras cinematográficas vai desde a ida ao cinema, que está se tornando tão comum aos adolescentes, principalmente no cenário atual, com a era dos Super Heróis e das sagas teens, com as quais os jovens muito se identificam, como podemos ver:

Longe de tratar o cinema apenas como mais um recurso didáticopedagógico, entretanto, a escola precisa assimilar que a ideia de educação para o cinema são formas similares de socialização: há um paralelo entre as relações construídas por alunos e professores e as relações construídas entre espectadores e filmes. Neste sentido, o professor de historia certa forma concorre com aquilo que o aluno aprende no cinema e outras mídias, inclusive TV e internet, que constituem um poderoso meio de influência. (MOCELLIN, 2009, p. 11)

Para Napolitano (2011, p. 11), "trabalhar com o cinema em sala de aula é ajudar a escola a reencontrar a cultura ao mesmo tempo cotidiana e elevada". Mas para que este trabalho consiga ocorrer de forma significativa, atingindo os objetivos de aprendizagem, é necessário que o professor consiga sistematizar este trabalho e que o mesmo seja continuo.

Para Baldissera e Ruinelli (2014, p. 25), os "historiadores não deveriam olhar para o cinema como fantasia ou entretenimento apenas, mas sim pensá-lo como uma das formas com as quais se construiu e se constrói o conhecimento histórico na atualidade".

Muitos filmes não foram considerados "históricos" na época em que foram realizados, mas depois de passado algum tempo, acabaram se tornando importante para história, pois eles não deixam de registrar características, valores, princípios da época em que foram produzidos. Acabaram sendo um retrato da época em si (BALDISSERA; RUINELLI 2014, p. 23). 
Percebemos que pela citação de Baldissera e Ruinelli, qualquer filme, e não apenas filmes considerados "históricos", podem ser trabalhados pelo professor, desde que estes tenham uma metodologia e um objetivo a ser alcançado através da utilização desta ou daquela obra cinematográfica, uma vez que é papel do professor "questionar, informar ou instigar os alunos a pesquisarem em fontes bibliográficas ou promoverem visitas a museus, exposições, sessões de cinema etc." (BRASIL, 1998, p. 88).

Para Napolitano (2011) é sempre um desafio para o professor que quer utilizar o cinema em sala de aula, pois este deve atuar como mediador entre o filme e os alunos. Em alguns casos, quando os alunos não são espectadores de filmes, ou não costumam assistir determinado gênero apresentado pelo professor, este terá que lidar com alguns casos de indisciplina na turma, muitas vezes, em outras parecerão entediados, emocionados. É a partir destas manifestações que o professor desenvolve seu papel através da conversação e de desdobramentos articulados com o filme. Outro ponto extremamente importante, é que o professor tenha claro com qual objetivo e porque está passando determinado filme para seus alunos, podemos ver que:

\begin{abstract}
Uma das justificativas mais comuns para o uso do cinema na educação escolar é a ideia de que o filme 'ilustra' e 'motiva' alunos desinteressados e preguiçosos para o mundo da leitura. Particularmente, acho que esta ideia deve ser problematizada. Em primeiro lugar, o desinteresse escolar é um fator complexo, envolvem aspectos institucionais, culturais e sociais muito mais amplos e não se reduz as insuficiências da escola e do professor, stricto sensu (NAPOLITANO, 2011, p. 15).
\end{abstract}

Por isso, é importante que o professor reflita sobre o público alvo de sua prática, e lembre-se que o filme não dever ser "para o próprio deleite intelectual e emocional do professor" (NAPOLITANO, 2011, p. 18). Também é importante conhecer o repertório cultural e de filmes destes alunos, para Napolitano, são cinco as perguntas básicas que o professor deve fazer antes de passar determinado filme:

1. Qual o objetivo didático-pedagógico geral da atividade?

2. Qual o objetivo didático-pedagógico específico do filme?

3. O filme é adequado à faixa etária e escolar do público alvo? 
4. O filme pode e deve ser exibido na íntegra ou a atividade se desenvolverá em torno de algumas cenas?

5. O público-alvo já assistiu a algum filme semelhante? (NAPOLITANO, 2011, p. 19).

Também é importante que o professor faça uma sondagem, para descobrir as preferências e vivências dos alunos:

A sondagem e a avaliação da cultura audiovisual (ou cinematográfica, mas especificamente) da classe não exigem pesquisa sociológica refinadíssima. Basta que o professor de maneira informal ou sistematizada, leve em conta algumas informações básicas: a) a qual faixa socioeconômica os alunos da sua escola/classe pertencem, em média; b) quais os hábitos de consumo e culturais da família; c) como funciona o consumo do cinematografo dos alunos (salas de cinema, aluguel de fitas de vídeo ou assistência de filmes na TV aberta ou a cabo); d) quais os gêneros cinematográficos preferidos; e) dentre os filmes vistos, quais os preferidos (NAPOLITANO, 2011, p. 80-81).

Desta forma percebemos que cabe ao professor extrair as potencialidades de um filme, reconhecendo o momento ideal para a utilização do mesmo, e perceber que em muitos casos não há a necessidade de se utilizar a obra completa, mas sim recortes que possam apresentar conceitos relevantes para a sala de aula. Também fica claro que, todo o filme é histórico e pode ser utilizado pelo professor, desde que obedeça certos padrões de classificação e uma metodologia adequada, que deverá ser respeitada e posta em prática pelo professor.

\section{Algumas possibilidades do uso do filme}

Quando se trabalha um filme em sala de aula, deve-se levar em consideração vários aspectos, que são de suma importância, para que este recurso possa ser trabalhado em sua totalidade de forma com que o aluno compreenda que deva ter um olhar crítico e reflexivo sobre as informações que Ihe chegam através dos meios de comunicação de massa, percebendo que os filmes não retratam uma verdade absoluta. Para Bittencourt (2011), alguns elementos que devem ser analisados com os alunos são as técnicas de produção, os grupos sociais que interagem na elaboração do filme, à política cultural, a 
sociedade que a produz e que a consome, observando todas as variáveis sociais, culturais e ideológicas. De forma geral para Kornis (1992, p. 248) há três aspectos imprescindíveis para a análise de um filme:

1. Os elementos que compões o conteúdo, como roteiro, direção, fotografia, música e atuação dos atores;

2. O contexto social e político de produção, incluindo a censura e a própria indústria cinematográfica;

3. A recepção do filme e a recepção da audiência, considerando a influência da crítica e a reação do publico segundo sexo, idade, classe e universo de preocupações;

A partir desta citação de Kornis, podemos perceber que trabalhar com filmes em sala de aula de aula vai muito além de simplesmente colocar o aluno no papel de expectador passivo. É necessário fazer um trabalho que se inicia com uma pré-análise e estudo do filme que vai ser apresentado e posteriormente ao assisti-lo continuar a discussão sobre temáticas pertinentes a obra trabalhada, do contrario podemos não aproveitar a totalidade deste recurso:

O potencial pedagógico eventualmente existente nos filmes tente a ser desperdiçado, a cair no vazio do questionário mecânico que visa uma transposição não menos mecânica dos elementos do conteúdo para a estrutura de conhecimento dos alunos (SEVERO, 2004, p. 115).

Para Bittencourt, não existe um modelo simplificado para introduzir os alunos na análise crítica do cinema, e é impossível deter-se apenas na análise do conteúdo do filme, o professor precisa ir além. Para a autora o docente deve observar:

1. A escolha do filme: identifica as preferências dos alunos, bem como as suas experiências e vivências como espectadores.

É preciso preparar os alunos para uma leitura crítica de filmes, começando por uma reflexão sobre os próprios a que eles assistem. Como escolhem um filme para assistir, ou quais os atraem? Preferem filmes que atinjam os sentidos e as emoções, para que não seja preciso nenhum trabalho intelectual? O que valorizam num filme: interpretação dos atores ou conteúdo? (BITTENCOURT, 2011, p. 376). 
Para a autora esses questionamentos são essenciais, principalmente para fazer com que os estudantes reflitam sobre que tipo de entretenimento estão consumindo e o porquê destas escolhas. É papel do educador, levar os alunos a questionarem a veracidade daquilo que estão assistindo.

2. Dossiê cinematográfico: $O$ dossiê cinematográfico ou desmontagem do filme resolveria o problema de muitos professores que desejam utilizar um filme como recurso em suas aulas, o tempo. Para Vesentini (2006) o dossiê trata-se de uma seleção de filmes com uma determinada temática a ser enfatizada:

\begin{abstract}
Denominei desmontagem a um trabalho prévio à projeção em sala de aula [...]. Trata-se de subdividir o filme em vários blocos, em pequenas cenas, atendendo a interesses de conteúdo. É difícil sua efetivação em sala de aula de aula, dado ao tempo exigido. Mas por ela o professor amplia tanto seu domínio sobre o filme, quanto define melhor uma bibliografia de leitura prévia para o trabalho com o filme (VESENTINI, 2006, p. 165).
\end{abstract}

A partir do que foi abordado até aqui, percebemos que o professor ao utilizar um filme em sala de aula precisa planejar todos os passos, ter bem claro para si, quais os objetivos visam atingir, quais os conteúdos e temáticas irá contemplar em seu trabalho, e principalmente incluir o aluno como sujeito participante deste processo, fazendo com que este possa analisar criticamente as informações que the chegam.

Para José Moran (apud NAPOLITANO, 2011, p. 34), os filmes podem estar sendo erroneamente utilizados pelos professores, e destaca cinco tipos de utilizações errôneas: TAPA BURACOS, quando há ausência de algum professor, ou ocorre um imprevisto e se decide colocar um filme para preencher o tempo, desta forma o aluno acaba sempre associando o assistir filmes, com o não ter aula. VÍDEO ENROLAÇÃO, passar um filme sem contexto com a aula, apenas para passar períodos e preencher a aula. VÍDEO DESLUMBRAMENTO, o professor que descobriu as maravilhas do cinema, mas o utiliza em todas as aulas e se esquece de outras dinâmicas importantes. VÍDEO PERFEIÇÃo procuram filmes, sem problemáticas e que representam a "verdade". Só víDEO, quando se passa um filme, sem depois discuti-lo com os alunos, ou sem ressaltar os pontos importantes. 
Moran, também, além de apontar estes erros na forma de utilizar o cinema em sala de aula, apresenta algumas propostas que considera significativas para a aprendizagem, tais como: SENSIBILIZAÇÃO, para introduzir um assunto, despertando a curiosidade dos alunos. ILUSTRAÇÃO, para ajudar os alunos a comporem cenários desconhecidos e distantes de sua realidade. CONTEÚDO DE ENSINO, quando o filme mostra algum assunto de forma direta e indireta e mediante a orientação do professor, o aluno pode interpretar a obra (MORAN apud NAPOLITANO, 2011, p. 35).

Outra proposta trazida por Severo (2004) é a ilustração significativa, onde o filme servirá como ilustração, mas essa ilustração será minuciosamente planeja, visando atingir um objetivo especifico. Para o autor a ilustração significativa:

Implicará, portanto escolhas, que dizer um recorte do universo de obras cinematográficas a disposição, de tal forma que essas obras venham a constituir um instrumento pedagógico valioso, em momentos estratégicos, na condução das aulas. Tais escolhas, contudo, deve anteceder um exame rigoroso da estrutura da disciplina, no caso, História, trabalhada (SEVERO, 2004, p.108).

Napolitano (2011), também sugere algumas formas de se trabalhar com o filme em sala de aula, observando o conteúdo, ou a técnica, ou a linguagem. O uso pelo conteúdo se divide quando a obra é usada como fonte histórica ${ }^{4}$ :

Um filme pode ser usado como fonte quando o professor direcionar a análise e o debate dos alunos para os problemas e as questões surgidas com base no argumento, no roteiro, nos personagens, nos valores morais e ideológicos. [...] quando está articulado a um conteúdo curricular ou a um tema específico, é o filme que vai delimitar a abordagem em questão (NAPOLITANO, 2011, p. 28).

Quando se utiliza um filme a partir de sua linguagem o professor não trabalha com as questões de conteúdo e representação do filme em si, mas sim com o objetivo de educar o olhar do espectador:

4 Como fonte histórica compreendemos que sejam, os, artefatos culturalmente construídos e repletos de intencionalidade pelos grupos que a originaram. Assim para Bloch: "Tudo que o homem diz ou escreve, tudo que fabrica tudo o que toca pode e deve informar sobre ele" (BLOCH, 2001, p. 79). 
As atividades com filmes em sala de aula podem, em si e por si, desenvolver habilidades e competências diversas, menos ligadas à problemática e discussão sobre o conteúdo do filme e mais às formas narrativas e aos recursos expressivos que o cinema, como linguagem, possui (NAPOLITANO, 2011, p. 29).

Napolitano também sugere que os professores selecionem e montem uma sequência anual dos filmes que serão apresentados, e que os mesmos façam articulações entre si. Para que os alunos percebam os filmes como uma fonte de aprendizagens é necessário que eles percebam que as obras estão articuladas e façam sentido entre si:

Sugerimos que o uso do cinema em sala de aula seja sistemático e coerente, e isso implica que os filmes sejam articulados entre si, sobretudo quando o espírito da atividade é a análise do filme como linguagem e fonte de aprendizado, mais do que catalisador de discussões (NAPOLITANO, 2011, p.79).

Para Gerson Severo (2004, p. 43), a problemática é ainda maior, visto que segundo ele: "A maior parte dos professores parece nunca ter buscado qualquer método pré-concebido para trabalhar com filmes". Sendo assim, percebemos que o professor compreende que o cinema pode ser trabalhado em sala de aula e o faz, porém utiliza-se apenas do senso comum, sem criar problemática entre cinema e História e cinema e ensino.

\section{Da tela de cinema à sala de aula: práticas docentes}

Para a realização desta pesquisa, foram visitadas as três escolas da Rede Municipal de Campo Bom, e os professores de História foram entrevistados individualmente. O grupo era formado por três homens e duas mulheres, que possuem idade entre 28 e 41 anos de idade, todos concursados no município.

Foram utilizadas entrevistas estruturadas, utilizando-se da conceituação de análise de dados e de uma pesquisa qualitativa no campo social, que foi construída a partir dos Saberes Docentes. Segundo Tardif (2002), em seu livro "Saberes Docentes e a Formação Profissional", a obra leva em consideração um conjunto de fatores que podem e influenciam as práticas docentes, como a formação desses profissionais, suas vivências pessoais, o currículo da rede que atuam seu cotidiano escolar e o entendimento que eles possuem de cinema 
como fonte histórica. As entrevistas foram divididas em três grandes blocos de saberes: Saberes da formação docente e disciplinares, curriculares e experienciais. Os professores foram entrevistados individualmente $\mathrm{e}$ as entrevistas gravadas e após transcritas, para serem analisadas a partir dos autores já citados.

Para esta entrevista os professores serão denominados professor: A, B, C, $D$ e $E$, sendo a seguinte correspondência para cada professor:

A: Professor Mestre em História e Especialista em Mídias na Educação, 29 anos, gosta de produzir filmes com os alunos.

B: Professora mestranda em História e Especialista em Estudos Clássicos, 28 anos, é considerada pelos alunos "a professora que passa filmes".

C: Professor Especialista em História da Arte, 28 anos, fã da banda Iron Maden, gosta de trabalhar com músicas em suas aulas.

D: Professora Especialista em Metodologia de História e Geografia, 41 anos, fã dos longas de Asterix e Obelix.

E: Professor Especialista em Educação a Distância, 36 anos, possui uma vasta videoteca. Utiliza sempre filmes originais, em sala de aula.

\section{1 - Saberes da formação docente e o cinema nas universidades}

Através das entrevistas constatamos que, todos os cinco professores possuem licenciatura em História e, também, possuem especializações na área da Educação, o que demonstra seu interesse em continuarem sua formação, especializando-se em áreas especificas do conhecimento. Para Fiorentini et al. (1998, p. 314), é a partir da década de 80 que se percebe a importância de se levar em conta os saberes docentes, incluindo dentre estes a formação do professor:

As pesquisas sobre ensino e formação de professores passaram a priorizar o estudo de aspectos políticos e pedagógicos amplos. Os saberes escolares, os saberes docentes tácitos e implícitos e as crenças epistemológicas, seriam muito pouco valorizados e raramente problematizados ou investigados tanto pela pesquisa acadêmica educacional como pelos programas de formação de professores. Embora, neste período, as práticas pedagógicas de sala de aula e os 
saberes docentes tenham começado a ser investigados, as pesquisas não tinham o intuito de explicitá-los e/ou valorizá-los como formas válidas. Neste sentido inicialmente, os professores foram questionados sobre conhecimentos provenientes de seus cursos universitários, que envolvessem a temática do cinema e seu uso em sala de aula. Todos os professores entrevistados relataram que não tiveram em sua graduação uma disciplina específica falando sobre cinema e seu uso em sala de aula. O professor $C$ relatou que em seu curso havia uma disciplina eletiva chamada Cinema, Literatura e História, porém ele não cursou a mesma.

Já os professores A, B e D, comentaram que em quase todas as disciplinas do curso de História os professores indicavam filmes sobre determinada temática, "Nas disciplinas de Medieval, e Estudos Clássicos, os professores traziam filmes que falavam sobre o período" (PROFESSOR A). A professora B relatou também que dentro dos componentes específicos do currículo, já era debatido como utilizar determinados filmes dentro do contexto de sala de aula: "Dentro do curso de História, nós utilizávamos o cinema como ferramenta de ensino e aprendizagem" (PROFESSOR B). O professor $\mathrm{E}$, relatou que seu contato com filmes, veio do curso de Comunicação, que fazia anterior a licenciatura, e que nessa formação ele aprendeu sobre a influência e as representações dos "vídeos", como ele nomeia.

Embora nenhum dos docentes tenha cursado disciplinas específicas sobre cinema, todos relataram que tiveram disciplinas de Estágio, que faziam a iniciação à docência e nelas eram debatidos e apresentados alguns recursos que poderiam ser utilizados para a obtenção de uma aprendizagem significativa.

Todos os professores entrevistados relataram que participam constantemente de formações continuadas (cursos, palestras, seminários, etc.), ofertadas pelo município de Campo Bom. Os professores relatam que formações divididas por área de conhecimento, quase não ocorrem, mas sim formações voltadas às temáticas para educação em geral. Os professores $B, D$ e $E$, relataram que a última formação que participaram tinha como temática central o 
Bullying ${ }^{5}$. O professor $\mathrm{E}$, ressaltou a relevância desta temática abordada, "Enriqueceu meu conhecimento, pois é outra área que na faculdade não é desenvolvida". Através desta fala podemos perceber outras lacunas que foram deixadas durante a formação, e que muitas vezes o professor não sabe como lidar quando chega à sala de aula.

\section{Os saberes experienciais e os recursos fílmicos}

Segundo Tardif (2002, p. 38), os saberes experienciais são os que resultam do próprio exercício da atividade profissional dos professores. Esses saberes são produzidos pelos docentes por meio da vivência de situações específicas relacionadas ao espaço da escola e às relações estabelecidas com alunos e colegas de profissão. Nesse sentido, "incorporam-se à experiência individual e coletiva sob a forma de habitus e de habilidades, de saber-fazer e de saber ser". Uma vez que:

De acordo com nossas análises, é impossível compreender a questão da identidade dos professores sem inseri-la imediatamente na história de seus próprios atores, de suas ações, projetos e desenvolvimento profissional. (TARDIF, 2002, p. 107).

As perguntas deste bloco foram elaboradas com o intuito de compreender se os professores entrevistados possuíam contato com filmes em seu cotidiano, quais os gêneros preferidos, se consumiam filmes de canais aberto ou a cabo, se mantinham como hábito idas ao cinema, enfim, se as obras cinematográficas se encontram presentes em seus programas pessoais, culturais e sociais, com o intuito de analisar o quanto os saberes experienciais influenciam em sua prática de sala de aula.

O primeiro questionamento levantado dizia respeito ao hábito de frequentar o cinema, se os professores o faziam e com que frequência. Dos cinco professores entrevistados, quatro relataram que frequentam o cinema habitualmente, entre uma vez por mês ou a cada três meses. O professor C relatou que não frequenta mais assiduamente o cinema em função do alto preço

5 Termo utilizado para descrever atos de violência física ou psicológica, intencionais e repetidos, praticados por um indivíduo ou grupo de indivíduos causando dor e angústia, sendo executadas dentro de uma relação desigual de poder. 
dos ingressos, os demais professores também comentaram sobre o preço dos ingressos, o que torna o cinema um entretenimento caro, limitando seu acesso ao público em geral.

Como o hábito de ir ao cinema, está interligado com o poder aquisitivo do professor, limitando muitas vezes seu acesso, o próximo questionamento, tinha haver com o hábito de assistir filmes em casa e/ou baixá-los na internet. Todos os professores relataram que tem o hábito de assistir filmes em casa semanalmente. O professor A relatou que baixa filmes da internet, principalmente os ditos "filmes históricos", de ficção científica, zumbis e filmes de guerra, está sempre buscando saber dos últimos lançamentos. A professora B relatou que não tem o hábito de baixar filmes, pois já teve seu computador infectado por vírus, mas os assiste pelo Netflix, relatou que atualmente precisa selecionar o que assiste em casa, em função de ter um filho pequeno, desta forma precisa observar a indicação do filme, e desta forma, limitou sua lista de filmes e do que assiste em casa. O professor $C$ possui uma biblioteca com mais de 200 filmes, em seu computador, que baixou da internet, prefere os filmes legendados, em função do áudio original. O professor C também assiste filmes pelo Netflix e alguns seriados. Já a professora $D$, também diminuiu as idas ao cinema, depois que teve filhos, em função de se tratar de um entretenimento caro. Diz-se eclética, no quesito de gênero e procura assistir filmes indicados pelos alunos, para buscar compreender o universo dos adolescentes, o último filme que assistiu, foi Ele está de volta, no Netflix, por indicação dos alunos. O professor $\mathrm{E}$ diz que todo o mês vai ao cinema, mas prefere ir às salas de Porto Alegre, pois há maiores promoções no preço do ingresso e descontos para professores. Ele costuma assistir filmes em casa, mas não baixa da internet, segundo ele:

Todos os filmes que eu tenho, eu fiz questão de comprá-los. Eu prefiro ter a capinha para eles olharem, gosto muito de valorizar isto, principalmente os direitos autorais, aquela coisa toda. Gosto de ensiná-los a consumir. A olhar a capinha, vale a pena, não pelo lado material, mas pelo lado de incentivar o consumo do filme (PROFESSOR E).

Os gêneros preferidos pelo professor $E$, são os ditos filmes históricos, drama e comédia. Ultimamente vem assistindo diversas series, através do Netflix. Diz 
sempre estar buscando assistir os últimos lançamentos do cinema, principalmente os da Marvel, pois acompanhava as $\mathrm{HQ}^{6}$, quando era adolescente. Considera bem interessante as trocas que ele consegue fazer com os alunos a partir deste tipo de filme, pois considera que, "O professor tem que entender um pouco do que o aluno vivencia".

\section{Os saberes curriculares: prática e reflexões}

O último bloco de análises compete aos saberes curriculares, que são os conhecimentos adquiridos ao logo da carreira docentes. Os saberes docentes e a prática pedagógica estão intrinsecamente relacionados, já que é no exercício da prática, uma atividade especializada, que eles são mobilizados, construídos e reconstruídos pelo professor a partir de uma ação dinâmica, ao ensinar.

O primeiro questionamento realizado estava relacionado com as ferramentas que os professores utilizavam em suas aulas, uma vez que "os saberes curriculares se apresentam concretamente sob a forma de programas escolares (objetivos, conteúdos, métodos), que os professores devem aprender a aplicar" (PROFESSOR E).

Todos os professores relataram que procuram diversificar suas aulas, não ficando presos apenas ao livro didático, mas sabendo como aproveitá-lo. As professoras $B$ e $D$, relataram que, desconstroem com os alunos algumas informações e erros dos livros didáticos, sendo que a professora $B$, sempre informa as editoras, quando encontra alguma informação errônea.

O professor $\mathrm{C}$ gosta de trabalhar com as obras de arte presente nos livros didáticos, pois são incomuns ao cotidiano do aluno. Tanto o professor $A$, como o professor $E$, comentaram que utilizam com bastante frequência das tecnologias disponibilizadas pelo município de Campo Bom, e que elas são facilitadoras do trabalho docente. O professor E mencionou, que quando chegou ao município, precisou adequar sua forma de dar aula, pois há apenas dois períodos de História, por semana, desta forma ele precisou realizar um trabalho mais dinâmico e produzir seu próprio material didático, adequando assim, suas aulas a nova realidade encontrada.

6 Histórias em quadrinhos.

História \& Ensino, Londrina, v. 27, n. 1, p. 307-333, jan./jun. 2021 
Os professores também relatam no geral, que trabalham com charges, música, HQ e cinema. A professora $B$, em função de sua área de estudo, prefere trabalhar com o que ela denomina fontes imagéticas, e destaca a importância de o professor conseguir se adaptar às turmas e ao ambiente de trabalho, afirmando que: "Às vezes o professor quer que os alunos se adaptem ao jeito dele dar aula, mas o professor também tem que se adaptar um pouco ao público em que está" (PROFESSORA B).

O professor A destacou que a didática das aulas, muda de acordo com o perfil da turma, mas que em todas, ele disponibiliza cópias, com o resumo da matéria, para não desperdiçar tempo copiando. A professora B, relatou que, no início de cada ano letivo faz, "um perfil de cada turma, nele eu coloco as preferências de filmes, programas de TV, livros, e a partir daí começo a planejar". Esse ponto é relevante, pois, vem de encontro com a proposta de Napolitano (2011, p. 80), "a sondagem e avaliação da cultura audiovisual da classe não exigem pesquisa sociológica refinadíssima. Basta que o professor, de maneira informal ou sistematizada, leve em conta algumas informações básicas".

A partir desses relatos percebemos também, uma preocupação em diversificar a maneira de se trabalhar com diferentes abordagens de ensino nas aulas de História. Ressaltamos também o aproveitamento, das tecnologias disponibilizadas pelo município, como a lousa interativa, mostrando interesse e capacitação, por parte dos professores. Destaco também, uma das falas feitas pela professora $\mathrm{B}$, que muito se relaciona com o oficio docente: "Ser professor, é meio que isto, viver cotidianamente com o sucesso e o fracasso". Dessa forma percebemos que ao analisarmos os instrumentos que os professores utilizam para suas aulas, podemos visualizar melhor seu perfil docente e como ocorrem suas práticas. Tardif (2002, p. 225), conceitua prática profissional, como sendo "o estudo do conjunto de saberes utilizados realmente pelos profissionais em seu espaço de trabalho cotidiano para desempenhar todas as suas tarefas".

\section{Protagonismo estudantil: produção de curtas metragens}

Esta proposta da realização de curtas metragens foi relatada tanto pelo professor A, quanto pela professora $B$. 
Na turma do professor A, quando ele trabalhou o conteúdo de Egito Antigo, ao invés de assistir com as turmas, filmes que retratassem este período, o professor propôs que os alunos produzissem seus próprios filmes, sobre o assunto. Nas palavras do professor:

Então os alunos criaram o roteiro, a gente fez roupas, fizemos a filmagem em um fundo verde e colocamos eles inseridos num contexto próprio do Egito. Foi uma experiência muito bacana, porque eles aprenderam muito mais do que se fosse só o professor falando ou através de um texto (PROFESSOR A).

Já a professora B, quando trabalhou as Revoltas na Primeira República, inicialmente ela começou sua prática com materiais visuais, utilizando charges da época, bem como HQ, que abordassem o assunto. Após, os alunos assistiram um compilado, de 1 hora e 20 minutos, do filme A Guerra de Canudos (1996), e responderam um questionário com algumas perguntas para reflexão sobre o filme. Em outro momento assistiram um trecho do filme Lampião o Rei do Cangaço (1964) e debateram o trecho em aula. Como finalização do conteúdo e atividade avaliativa, os alunos se dividiram em grupos e cada um deveria produzir, um curta metragem sobre uma das revoltas abordadas em aula: Revolta da Chibata, Canudos, Contestado ou Cangaço. Os alunos poderiam escolher se eles mesmos atuariam em seus filmes, se utilizariam fantoches, bonecos, etc.

Segundo a professora, a maioria dos grupos escolheu representar a Guerra de Canudos, em função de ter visualizado a mesma através do filme que assistiram. Em sua opinião, foi uma atividade muito significativa para os alunos, "alguns confeccionaram túnicas para se parecer com Antônio Conselheiro [...] os grupos se puxaram, teve grupos que no meio do filme criou propagandas, comerciais, que imaginavam que poderiam existir na época" (PROFESSORA B).

A prática relatada pelos professores $A$ e $B$, como podemos analisar, foi um momento que além do envolvimento dos alunos, precisou do planejamento articulado por parte dos professores, pois se os alunos não tivessem compreendido o conteúdo, não poderiam representá-lo através das câmeras. 
Como destaca Bittencourt (2011, p. 375), não existe uma maneira simplista de se realizar um trabalho significativo, principalmente no que diz respeito ao cinema:

Fica evidente que não existe um modelo simplificado para introduzir os alunos na análise crítica da imagem cinematográfica, mas pode-se destacar a impossibilidade de deter-se apenas na análise do conteúdo do filme. É preciso ir além.

Também podemos perceber pelo relato da professora $B$, que ela fez recortes no filme $A$ Guerra de Canudos, deixando apenas trechos que considerava necessário para a compreensão do conteúdo. Esta intervenção nos filmes, tão pouco explorada pelos professores, muitas vezes é fundamental para otimização do tempo em sala de aula, "o professor precisa perder o medo, o respeito ao vídeo, assim como ele interfere num texto escrito, modificando-o, acrescentando novos dados, novas interpretações, contextos mais próximos do aluno" (MORAN apud NAPOLITANO, 2011, p. 35).

Quanto à proposta de elaboração de um filme produzido totalmente pelos alunos, consideramos de extrema importância este protagonismo estudantil, pois para que pudessem executar a proposta, os alunos precisaram observar importantes elementos da produção cinematográfica como composição do conteúdo, roteiro, figurino, cenários, atuação e filmagem. Uma vez que "o filme pode ser produzido pelos próprios alunos, situação que possibilita a compreensão do processo de produção das imagens cinematográficas" (BITTENCOURT, 2011, p.376). Também ressaltamos a importância de o professor conhecer a linguagem cinematográfica e recursos tecnológicos, como programas de edição de imagem e som, conseguindo assim, aprimorar a produção dos alunos. Como no caso do professor $A$, que é especialista em Mídias na Educação e tem o domínio da tecnologia da tela verde, utilizada para compor cenários. Para Moran, nesses momentos de produção de vídeo, a aprendizagem torna-se significativa, pois o aluno se vê atuante e vivenciando o conteúdo:

As crianças adoram fazer vídeo e a escola precisa incentivar ao máximo a produção de pesquisas em vídeo pelos alunos. A produção em vídeo tem uma dimensão moderna, lúdica. Moderna como meio contemporâneo, novo e que integra linguagens. Lúdica pela miniaturização da câmera, que permite brincar com a 
realidade, levá-la junto para qualquer lugar. Filmar é uma das experiências mais envolventes, tanto para crianças, como para adultos. Os alunos podem ser incentivados a produzir dentro de uma matéria, ou dentro de um trabalho interdisciplinar (MORAN apud NAPOLITANO, 2011, p. 36).

Nesse sentido podemos perceber como um ambiente significativo de aprendizagem, que propicie o protagonismo do aluno, é importante para uma boa prática e para bons resultados.

\section{Filmes, debates e questionários:}

Todos os professores entrevistados relataram que utilizam filmes ou trechos desses para finalizarem com debates/seminários ou questionário. Uma das práticas desenvolvidas pela professora B foi com a temática de Segunda Guerra Mundial. Como existem muitos filmes sobre esta temática, ela estudou bastante a escolha do filme, e os alunos assistiram o longa $A$ vida é bela (1997), segundo a entrevistada a escolha se deu em função de, "escolher um filme que fosse um clássico, e que a grande maioria não tenha assistido, que fosse contra os padrões hollywoodianos. Então encontrei, A vida é bela, que é uma narrativa italiana" (PROFESSORA B).

Após terem assistido ao filme, a professora realizou um momento de debate com os alunos, no qual traçaram paralelos entre o fascismo/nazismo e o filme, e após, divididos em grupo os alunos encenaram um trecho do filme. A professora comenta, que antes de assistir ao filme, explicou para os alunos que o início da narrativa pareceria mais enfadonha, mas que depois o filme ficaria mais interessante, e relatou ainda que os alunos se emocionaram muito com os personagens centrais da trama, "eu não disse para os alunos, que era impossível manter uma criança daquela forma, em um campo de concentração, mas penso que este filme foi bastante válido para eles" (PROFESSORA B). Para Severo é muito importante quando o aluno se identifica com os personagens, pois, "uso do cinema poderá envolver afetivamente e emocionalmente o aluno, feito que não pode ser desprezado, criando pré-condições, ambientes significativos, para que o mesmo seja motivado a aprender" (SEVERO, 2004, p. 68). Percebemos que inicialmente ouve um estranhamento por parte dos alunos ao assistirem o filme, 
pois era uma narrativa que não estavam acostumados, mas com o incentivo da professora, e o trabalho desenvolvido antes de assistir ao filme, conseguiram aproveitar a obra, envolvendo-se com o enredo, para Napolitano (2011, p. 22) "ao compreender as convenções narrativas e prever possíveis desenvolvimentos na história, o que Ihes será benéfico nos primeiros contatos com textos escritos".

Continuando na linha de filmes que abordem as Guerras Mundiais, o professor $E$, relata que para a escolha dos filmes recorre a seguinte didática:

Levo vários títulos sobre a mesma temática e faço uma breve sinopse de cada um deles e pergunto qual eles querem assistir, faço uma votação, assim bem democrático. Quem já viu o filme, o viu em um contexto diferente, e agora com o conteúdo já trabalhado terá uma nova percepção. Quem já foi meu aluno já está acostumado, sabe que funciona assim (PROFESSOR E).

Os últimos filmes escolhidos pelos alunos do professor $\mathrm{E}$, foram $O$ menino do pijama listrado (2008) e Cavalo de Guerra (2012), sendo que o último, que aborda sobre a Primeira Guerra, ele utilizou para mostrar como funcionavam as três fases da guerra. O professor $E$, ainda destaca que, como sempre passa o filme como fechamento do conteúdo, não pede textos ou resumos do filme, nem passa questionários para os alunos responderem, segundo ele "eu a fiz isso de pedir resumos e questionários, mas daí os alunos assistiam ao filme sem vontade, obrigados, e daí perdia todo o sentido" (PROFESSOR E). Apesar de não solicitar esses registros escritos para os alunos, relata sempre realizar um debate, relacionado o conteúdo ao filme.

Outro filme que aborda a Primeira Guerra, que é utilizado pela professora B é FlyBoys: nascidos para voar (2006), segundo ela, este longa também rende boas vivências e debates, com as turmas. Já no conteúdo de Revolução Russa, ela recorre à análise de propagandas soviéticas e a filme Trotsky: A Revolução Começa na Escola (2010), após um debate sobre o filme a professora também passa um questionário para os alunos identificarem conceitos da Revolução Russa presentes no filme.

A professora D gosta e trabalhar trechos de filmes da Marvel sobre os super-heróis, e os relacionam com a construção dos heróis nacionais, a construção das ideologias, entre outras temáticas, que segundo ela, os alunos compreendem melhor, quando traçados paralelos com algo que eles se 
identifiquem, como o caso dos filmes de super-heróis, que está tão presente no cenário atual.

O professor $C$ relatou, que um dos filmes, que ele sempre trabalha em suas aulas, todos os anos, é Lutero (2004), segundo o professor:

Eu acho ele bem didático, pois mostra todos os detalhes da reforma protestante, aquilo que em uma aula de História tradicional tu não ia utilizar. Eu gosto muito de utilizar ele, por mostrar o surgimento das várias religiões (PROFESSOR C).

Segundo o professor, após passar o filme ele propõe debates e pede um resumo do filme relacionando-o com o conteúdo, ou passa questões para os alunos responderem. Um filme que o professor $\mathrm{C}$ relata dar bastante certo com suas turmas, é O Incrível Exército de Brancaleone (1966), ele passa este filme para abordar o conteúdo de Idade Média e relata que mesmo sendo um filme antigo, em função de ele ser engraçado, os alunos gostam bastante e conseguem compreender e visualizar elementos como: os costumes da cavalaria, a peste negra, as relações sociais do feudalismo e o poder da Igreja Católica, contexto histórico é a Baixa Idade Média, quando o trinômio peste, fome e guerra marca a crise do século XIV e do próprio sistema feudal. Após assistido ao filme aplica a mesma dinâmica de debate, resumo ou questões. Napolitano, também propõe que se trabalhe com o filme a partir de questões bem elaboradas e articuladas com o conteúdo:

A análise pode ser elaborada na forma de um conjunto de questões (assertivas ou interrogativas) que dirija o olhar do aluno para aspectos mais importantes do filme, baseado nos princípios, no conteúdo disciplinar e nos objetivos da atividade proposta. Não é necessário um grande número de questões, mas é fundamental que sejam bem direcionadas e formais, pois são neles que encontramos a "mensagem" e os valores veiculados com o filme. (NAPOLITANO, 2011, p.85-86).

Outro filme que é escolha do professor E, trata-se de Jazão e os argonautas (1963), para ele o conteúdo de mitologia é bastante complexo para os alunos, e através do filme ele acredita que os alunos consigam visualizar esta relação. Ele opta por esta produção, por ser um clássico e chamar a atenção dos alunos pela tecnologia utilizada na época, uma mistura de personagens reais com monstros 
de stop motion, a sequência em que sete esqueletos brotam do chão e atacam os heróis ainda é considerada como uma das maiores realizações em efeitos especiais cinematográficos do Século $X X$. O professor relata que os alunos sempre questionam "sor, aquilo ali são bonecos de massinha? Que tri!". Ele ainda destaca que "esse filme é muito melhor que o Percy Jackson e outros desenhos da Disney que ensinam totalmente errado" (PROFESSOR E). Então prefere versões mais antigas sobre as mitologias. Porém, como já abordamos anteriormente, o filme possui uma linguagem própria e não tem compromisso em retratar fatos históricos, tal qual, aconteceram, pois, "cinema é metáfora" (SEVERO, 2004, p. 128), e o

\footnotetext{
Potencial pedagógico, do filme, estará mais no professor, em sua capacidade de reconhecer o momento ideal de introdução de um filme e criatividade para extrair-Ihe potencialidade, do que do próprio filme.
}

Sendo assim, o filme de Percy Jackson, poderia ser utilizado, sem nenhuma perda pedagógica, mas precisaria da interferência do professor, estimulando os alunos a analisarem a narrativa proposta pelo filme, o que está de acordo com o conteúdo previamente trabalhado, o que não está, por quê não está. Esta é a função do docente, atuar como mediador.

Os professores C, D e E relatam também que gostam de passar o filme Adeus, Lênin! (2003), e ressaltam a importância de preparar os alunos para assistirem este tipo de narrativa, mais "lenta", em função de ser uma produção alemã, com uma narrativa diferente daquela que os alunos estão acostumados. Para os professores através desta narrativa os alunos podem compreender a diferença, não apenas teórica, entre comunismo e capitalismo, mas também, a diferença de hábitos das pessoas e sua maneira de ver o mundo, em função da organização política e social de seus país. Os professores relataram que utilizam esses filmes após trabalharem todo o conteúdo, e após promoveram discussões, para destacarem trechos relevantes. Para Napolitano (2011, p. 28), "O importante é não ficar apenas no filme ilustração, mas usar criticamente a narrativa e as representações fílmicas como elementos propulsores de pesquisas e debates temáticos". 


\section{Momento de socialização: ida ao cinema}

A professora $B$, relatou que com as turmas de $6^{\circ}$ ano, gosta de realizar um momento de socialização, como a ida ao cinema, uma vez que estes alunos ainda estão se adaptando ao novo formato escolar, dividido por disciplinas, vários professores, novos colegas e uma realidade totalmente diferente da que estavam habituados. Então a professora sempre observa se estão em cartaz no cinema do CEI (Centro de Educação Integrada), que pertence ao município, e disponibiliza, uma vez por mês, sessões gratuitas para as escolas, se está passando algum filme que ela possa relacionar com o conteúdo.

Neste ano levou suas turmas para assistirem à produção brasileira Os dez Mandamentos (2016). A professora conta que foi criticada por alguns colegas, por escolher um filme, que eles consideraram, de conotação religiosa, porém ela justificou que estava terminado o conteúdo de Egito Antigo e iniciando o estudo sobre o povo hebreu e o filme, em questão, abordava entre outras temáticas, choque de crenças e realidade entre as duas culturas, desta forma o longa estava sim, relacionado com o conteúdo. Para Napolitano, quando se trabalha com filmes voltados para grandes públicos, como é o caso desta produção que os alunos foram assistir, cabe ao professor conduzir a análise-reflexiva dos alunos, quanto a mensagem que o filme quis passar e o que, ou não, relacionar com o conteúdo de aula:

É preciso que o professor estimule o debate sobre a mensagem principal que o diretor ou o sistema que produziu a obra quis fixar no receptor. Quase sempre estas mensagens são de natureza político-ideológica ou ético-moral e, nesse sentido, o cinema tem uma função ideológica cognitiva fundamental no mundo moderno. (NAPOLITANO, 2011, p. 94).

Segunda a professora A, o "ritual", de comprar o ingresso, se dirigir ao cinema, comprar pipoca e assistir ao filme, é extremamente valido e significativo para os alunos, "eles precisam desses momentos de socialização". A educadora também relatou, que as turmas comentaram tanto, posteriormente, sobre a ida ao cinema, que agora todas as turmas estão pedindo para irem também. Para Bittencourt (2011, p. 236) é extremamente importante estes momentos de socialização, pois o aluno se percebe como um sujeito social, pois "ela permite às 
pessoas inserir-se em um grupo e realizar trocas, intervindo na definição individual e social, na formação pela qual o grupo se expressa".

Destaco também, que mesmo a cidade tendo o cinema comunitário e o dia de isenção de ingresso para os estudantes, a professora B foi a única que relatou ter levado seus alunos ao cinema. Também vai ressaltar que a escola onde a professora trabalha é próxima ao cinema, não necessitando gastar com transporte para levar os estudantes ao local.

Cabe ao professor em fazer essa transposição entre os personagens reais e os fictícios, e extrair as potencialidades da obra, relacionado-a com o conteúdo, podendo articular o filme biográfico, com a elaboração de análise de obras literárias, sobre a mesma personalidade. Fazendo com que o aluno perceba a diferença entre a elaboração de ambos.

Das propostas citadas até aqui, podemos perceber que os professores possuíam um objetivo ao qual buscavam atingir, através de determinada sequência didática, bem como planejaram antecipadamente para consegui executar seu planejamento, demonstrando a importância da articulação entre a aula de História e o uso de filmes, como já nos trouxeram Severo e Napolitano.

Todo o docente que assim faz torna sua aula mais dinâmica, atraente e os objetivos traçados têm mais chance de serem alcançados. Além disso, consegue tornar a sala de aula um verdadeiro local de pesquisa e de aprendizagem mútua (de professor para aluno e de aluno para o professor). Na construção do planejamento o professor tem como checar mais precisamente as características de sua turma bem como suas dificuldades, para a partir daí saber como passar os conteúdos disciplinares com maior êxito tanto para si como para o alunado, como relatado pela professora $B$, que traça um perfil da turma, lavando em

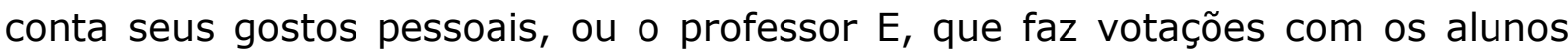
para a escolha dos filmes.

\section{Considerações finais}

Esta pesquisa buscou analisar propostas relativas ao uso do cinema em sala de aula e como este recurso pode ser uma ferramenta para uma aprendizagem significativa, bem como compreender como os saberes docentes constroem o 
perfil do professor e interferem diretamente em sua prática pedagógica e na escolha dos recursos que este utiliza em suas aulas.

Ressaltamos que este projeto não é detentor da verdade, é apenas o início de um estudo que traz algumas sugestões do uso do cinema, bem como sua relevância como recurso didático para as aulas.

Constatamos que o cinema já vem sendo utilizado em sala de aula, pelos professores de História, há muito tempo, desde 1912. Porém esta prática, poucas vezes foi refletida e debatida, e poucas foram as analises que visassem propostas didáticas que estão sendo aplicadas do dia-a-dia de uma escola, e que proporcionam uma aprendizagem significativa. O que gerou um uso superficial dos filmes, apenas para ilustrar o passado, uma espécie de "máquina do tempo".

Observamos que todos os professores, planejam antecipadamente as atividades que propõe as suas turmas, além do mais as atividades propostas possuem objetivos bem delineados, o que é fundamental para uma boa aula. Pois vários citaram a produção de filmes, o recorte de obras, a análise de recortes diferentes, a produção de maquete, entre outros, que só são possíveis de se executar com um planejamento prévio. Percebemos também um interesse dos professores, quanto a temática cinema, e como esses, apesar de formados, continuam buscando informações, tanto em cursos, quanto em sites e artigos, sobre a linguagem do cinema, sobre novos métodos de ensino e até mesmo sobre novos filmes, que acrescentem em sua biblioteca. Demonstrando assim, que um bom professor, é um eterno pesquisador, na busca por aprimorar sua prática pedagógica.

Percebemos pelos relatos, que os docentes buscam inovar nas metodologias escolhidas para o uso do cinema em sala de aula, não o utilizando apenas como ilustração, o que demonstra pesquisa e leitura sobre esta temática e a influência de todos os outros saberes e experiências que carregam consigo. Esperamos que essa pesquisa tenha contribuído para a compreensão da importância do cinema como fonte histórica. Bem como tenha conseguido refletir sobre os usos que os professores de História que os professores fazem a partir dos filmes e como esses colaboram para uma aprendizagem significativa e eficaz.

Com essa pesquisa, percebemos que a escolha por se utilizar o cinema em sala de aula, está diretamente ligado com os Saberes Docentes trazidos por 
Maurice Tardif, que serviram de base para estruturar as entrevistas da presente pesquisa. Uma vez que pudemos perceber que os professores são constituídos por distintos saberes e influências. Nesses casos não existem exceções, o pessoal do professor está vinculado no seu profissional, e vice-versa, ambos trabalham unidos para que se construa "o professor". Dessa maneira, percebemos o professor sofre influências tanto de sua formação, quanto de suas vivências e essas auxiliam ou interferem no desenvolvimento de sua prática docente.

Sendo assim, no decorrer dessa pesquisa que culminou com as entrevistas e posterior análise, conseguimos visualizar que nas escolas pesquisadas no município de Campo Bom-RS, o cinema vem sendo utilizado em toda a sua totalidade, como forma de tornar o ensino-aprendizagem de História mais significativo utilizando um elemento que está no cotidiano do aluno, como os filmes, proporcionando momentos onde os discentes puderam questionar, analisar, comparar, irem ao cinema, e até mesmo produzirem filmes, contribuindo com o principal objetivo do PCN, de formar cidadãos críticos que percebam a realidade a sua volta. Tudo isso devido aos profissionais da área de História, que demonstram possuir vários saberes que culminaram para essas boas práticas docentes, e que muito embora possamos perceber um perfil distinto de cada professor e uma forma singular de compreender o ensino e de categorizar o lugar do cinema nesse processo de aprendizagem, todos mostraram-se interessados em aprender, para melhor ensinar.

\section{Referências}

BALDISSERA, José Alberto; RUINELLI, Tiago de Oliveira. 'Tempo e magia': a história vista pelo Cinema. Porto Alegre: Escritos, 2014.

BITTENCOURT, Circe Maria Fernandes. Ensino de história: fundamentos e métodos. São Paulo: Cortez, 2011.

BLOCH, Marc. Apologia da história ou o ofício do historiador. Rio de Janeiro: Jorge Zahar, 2001.

BRASIL. Ministério da Educação. Parâmetros curriculares nacionais: terceiro e quarto ciclos do ensino fundamental - história e geografia. Brasília: MEC, 1998. 
FIORENTINI, D. \& SOUZA e MELO, G.F. Saberes docentes: Um desafio para acadêmicos e práticos In: GERALDI, C. (org). Cartografias do 42 Educação \& Sociedade, ano XXII, no 74, Abril/2001 trabalho docente: Professor(a)pesquisador(a). Campinas: Mercado das Letras, ALB, 1998.

KORNIS, Mônica Almeida. História e cinema: um debate metodológico. Estudos Históricos, Rio de Janeiro, v. 5, n. 10, p. 237-250, 1992.

MOCELIN, Renato. História e Cinema: Educação para as mídias. Porto Alegre: Editora do Brasil, 2009.

NAPOLITANO, Marcos. Como usar o cinema em sala de aula. 5. ed. São Paulo: Contexto, 2011.

SEVERO, Gerson Egas. Com Lumière em sala de aula: uma contribuição.

Erechim: Edifapes, 2004.

TARDIF, Maurice. Saberes docentes e formação profissional. Petrópolis: Vozes, 2002.

VESENTINI, Carlos Alberto. História e ensino: o tema do sistema de fábrica visto através de filme. In: BITTENCOURT, C. (org.). O saber histórico em sala de aula. São Paulo: Contexto, 2006. p. 163-174. 